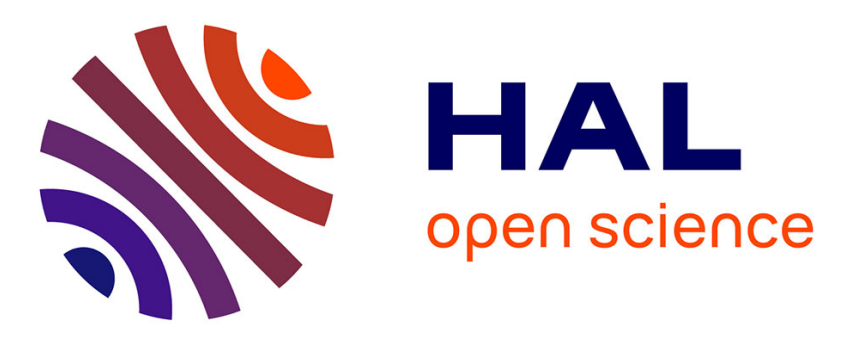

\title{
Studying impacts of travelling wave shape on pumping for active cooling
}

\author{
Julien Fontaine, François Pigache, Marc Miscevic, Jean-François Rouchon, \\ Frederic Topin
}

\section{- To cite this version:}

Julien Fontaine, François Pigache, Marc Miscevic, Jean-François Rouchon, Frederic Topin. Studying impacts of travelling wave shape on pumping for active cooling. IEEE International Workshop of Electronics, Control, Measurement, Signals and their application to Mechatronics (ECMSM), May 2017, Donostia, Spain. hal-01792919

\section{HAL Id: hal-01792919 \\ https://hal.science/hal-01792919}

Submitted on 16 May 2018

HAL is a multi-disciplinary open access archive for the deposit and dissemination of scientific research documents, whether they are published or not. The documents may come from teaching and research institutions in France or abroad, or from public or private research centers.
L'archive ouverte pluridisciplinaire HAL, est destinée au dépôt et à la diffusion de documents scientifiques de niveau recherche, publiés ou non, émanant des établissements d'enseignement et de recherche français ou étrangers, des laboratoires publics ou privés. 


\section{Studying impacts of travelling wave shape on pumping for active cooling}

\author{
Julien Michel Fontaine, François Pigache, \\ Marc Miscevic, Jean-François Rouchon \\ Université de Toulouse; INP, UPS ; \\ LAPLACE (Laboratoire Plasma et Conversion d'Energie) \\ CNRS ; UMR 5213 \\ Toulouse, FRANCE \\ Email: fontaine@laplace.univ-tlse.fr
}

\author{
Frédéric Topin \\ Aix-Marseille Université \\ IUSTI (Institut Universitaire \\ des Systèmes Thermiques Industriels) \\ CNRS ; UMR 7343 \\ Marseille, FRANCE
}

\begin{abstract}
A planar peristaltic pumping device is studied in the scope of CPU cooling. The wall shape of the channel is imposed by a set of actuators. The purpose is to study the most appropriate driving conditions in order to optimize the coolant flow rate. Among several parameters such as frequency, wave amplitude or position and size of actuators, the phase shift of actuator supply are particularly studied. The theoretical analysis of the flow rate is performed with a simplified computational model. To validate this approach, results are compared to 3D CFD numerical simulations. In some specific operating conditions, it is demonstrated that the simplified approach allows to identifying the appropriate driving conditions.
\end{abstract}

Index Terms-peristaltic pumping; heat transfer enhancement; active cooling; embedded electronic systems; forced pseudotravelling wave

\section{INTRODUCTION}

Due to increasing power density, thermal management of embedded electronics systems is nowadays a major challenge. Since 2005, a lot of efforts are conducted to improve the efficiency and avoid thermal losses of CPU with microarchitecture and software solutions [1]. An efficient thermal control of the microprocessor temperature also reduces the failure rate [7] and the global power consumption [2]. In many applications, the cooling solution must be compliant with the requirements of embedded systems such as reliability, MTBF, low consumption, compactness and lightness.

In this context an innovative solution called OnduloTrans [8] technology is proposed to cool electronic chips such as a processor (Fig. 1). It consists in a single-phase liquid heat exchanger directly put on the heat source surface. Its function is double: on the one hand it pumps the fluid and on the other hand it enhances the heat transfers between the chip and the coolant by dynamic change of the channel thickness. OnduloTrans principle consists in a flat pumping chamber with dynamic movement of one wall to produce a pseudotravelling wave and therefore a peristaltic pumping. According to the preliminary theoretical results [5], high relative amplitude displacement of such a wave, compared to the chamber thickness, leads to both high heat transfer coefficient and flow rate (Fig. 2).

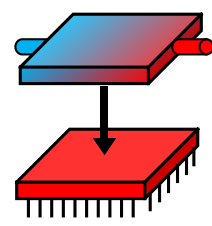

(a) Position of the device on the chip

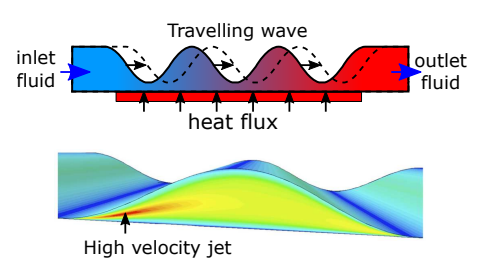

(b) Sketch of the principle and field of the velocity vector amplitude [5]
Fig. 1. Principle of the OnduloTrans technology

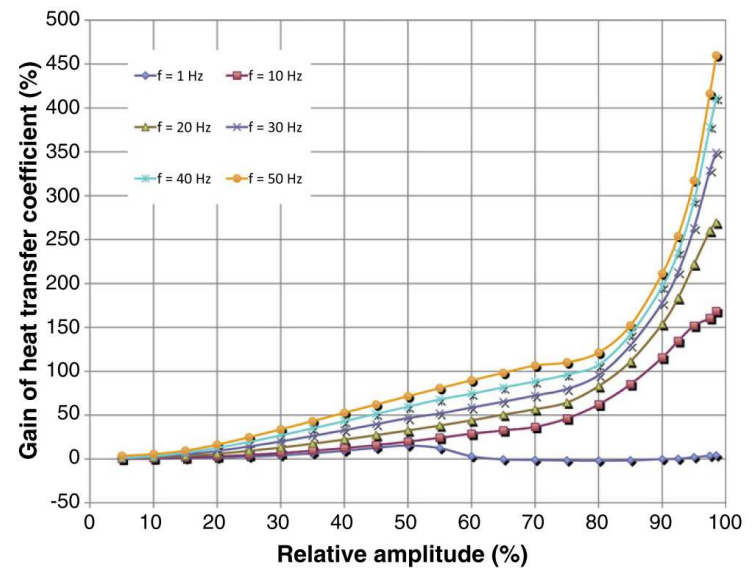

Fig. 2. Gain of heat transfer coefficient function of amplitude displacement of the travelling wave [5]

The requirement of a solution size compatible with the processor dimensions implies the use of distributed actuators to produce a forced pseudo-travelling wave. With a set of several actuators, many parameters allow to modifying the travelling wave behaviour and consequently the performances of the device. This paper will focus on the impact of phase shift control between every actuator on the flow rate. An analytical model is presented and compared to 3D CFD numerical simulations, an optimal configuration is determined. 


\section{THE STUDIED PERISTALTIC PUMPING}

\section{A. Origin of this specific wave shape}

The thermal power evacuation in the liquid depends on, the fluid properties, the temperature difference between inlet and outlet, and the flow rate (eq.1). With the OnduloTrans solution used for CPU cooling, transfer coefficient above $10000 W / K . m^{2}$ could be achieved. With such high transfer coefficient the overall temperature difference between the top of the chip and the liquid is very small. Thus, in eq. 1 the $\Delta T$ can be approximated to the temperature gradient of the chip. A maximal convenient temperature gradient of $10 \mathrm{~K}$ is recommended on the die surface. As a consequence, the thermal power dissipated by the device will be mainly limited by the flow rate.

$$
P_{t}=\rho c_{p} \Delta T Q
$$

The actuation of the wall must be very efficient for satisfying the high flow rate requirement. To dissipate a heat power above $50 \mathrm{~W}$, a minimum flow rate of $200 \mathrm{~mL} / \mathrm{min}$ is required [3]. It leads to have a wave amplitude of several hundred micrometers. Considering this displacement amplitude and the size specifications compatible with the processor dimensions, it implies the use of distributed actuators to produce a flow [3]. Finally, the compactness requirement is essential for embedded system and the consequence is a limited number of actuators. The consequence is that an ideal sinus travelling wave cannot be achieved.

\section{B. Hypothesis}

With such conditions, the deformation of the wave shape is quasi-static, no resonance or wave propagation are exploited. Moreover, the very low discretization of the wave leads to a pseudo travelling wave working like valves. This type will be qualified as forced pseudo-travelling wave.

In this article it is supposed that the distributed actuators have a rectangular footprint on the elastic wall. All positions and sizes of all these footprints could be choose individually. In the present studied actuators are supposed perfect, which means that footprints keep their planarity and displacements are perfectly controlled. No fluid-structure interaction are taken into account, the wall is rigid enough to avoid inflation.

\section{Geometry of the simulated set-up}

In the studied case, all footprints are identical, equally spaced along the flow direction (x direction) and symmetrically placed in the transverse flow direction (y direction) (Fig. 3). For the simulated setup 3 actuators are chosen for convenience of presentation of results by limiting the number of phase shifts at two. The size of footprints represent $20 \%$ of the Lx length of the pumping chamber and $80 \%$ of the Ly length. The relative displacement amplitude is fixed at $95 \%$.

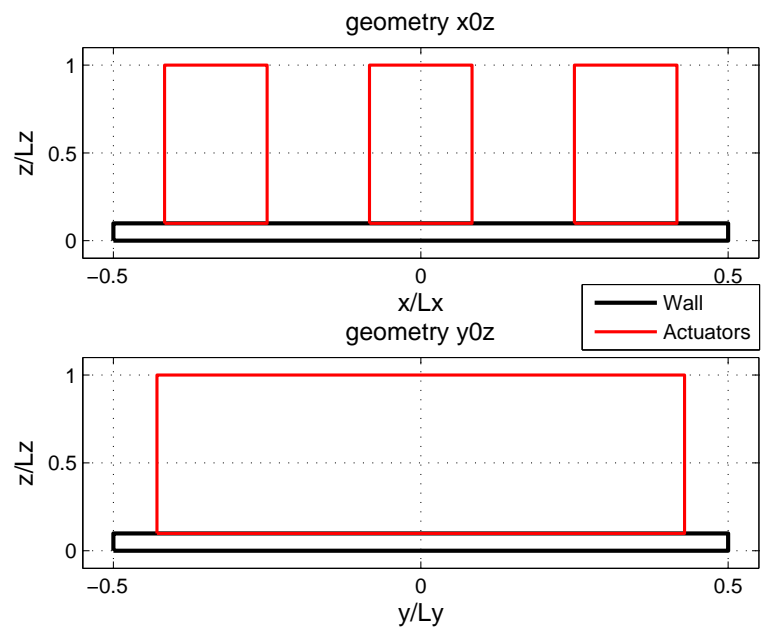

(a) Geometry

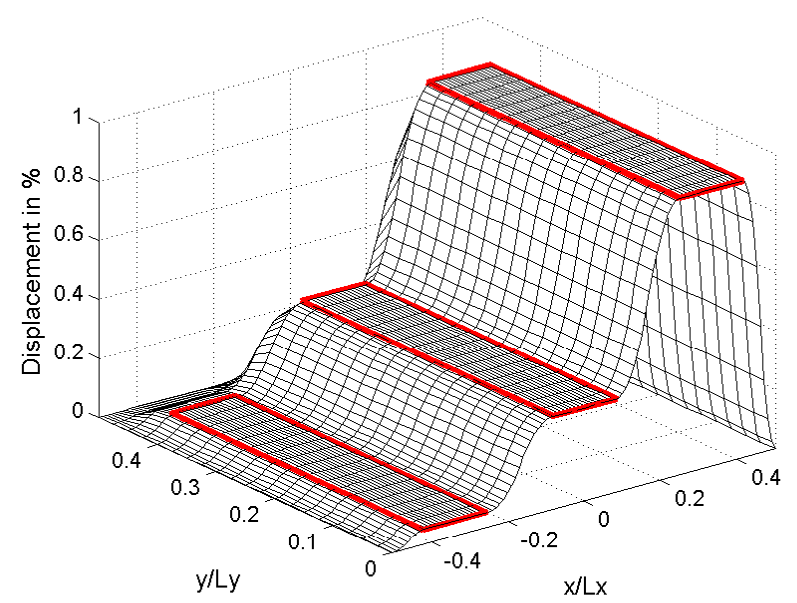

(b) 3D view of the wave shape

Fig. 3. Studied peristaltic pumping, example with 3 footprints with adimensional lengths

\section{Deformation parameters}

To control the shape of the wave, time dependant functions define the $\mathrm{z}$-displacement of the three footprints.A same displacement signal is chosen for all three actuators which could be for any waveforms such as sinus, triangle or square. This study will focus on a square waveform because of its high resulting flow rate. Finally the time phase shift signal will be controlled between all three actuators. As recommended in [3] the frequency is fixed at $15 \mathrm{~Hz}$.

\section{COMPUTATIONAL METHOD FOR FLOW RATE EVALUATION}

\section{A. Principle}

A theoretical formula to evaluate the flow rate is described in [4] for a peristaltic pumping with a square wave-like deformation. This evaluation has been experimentally validated in [6]. The advantage of this method is to take fluid phenomenon 


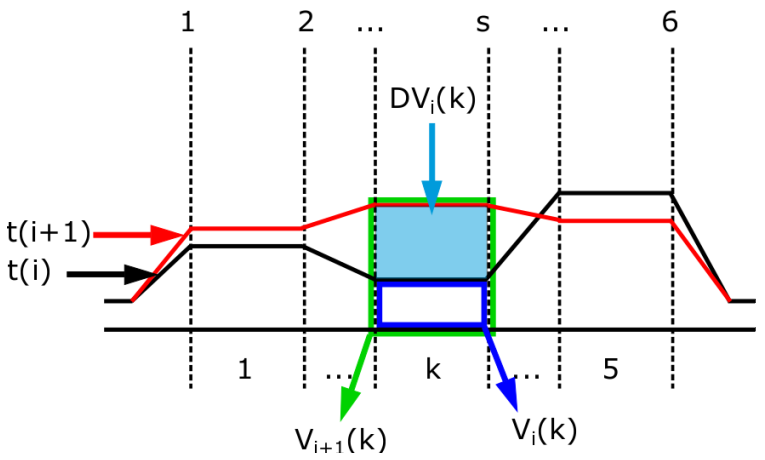

Fig. 4. Principle of the computational model

into account. But, like other methods, it supposes a perfect travelling wave in the sense that the wave shape is perfectly propagating in the flow direction.

To evaluate the flow rate without the use of elements methods and meshing a simple algorithm has been developed. The advantage of this solution is that it can be easily implemented in an optimization algorithm in order to deduce the optimal configuration required for the maximal flow rate.

In this computational model, the flow rate is calculated from volume consideration. The pumping chamber is cut in several sections along the flow direction. For each section, the volume difference between two consecutive instants is evaluated to go through the inlet or the outlet. The height of the wall (zdirection) between two sections defines where the volume is moved (Fig. 4). In this study the section length is matching with the footprint size, but finest cutting could be taken if needed for other complex geometries.

Limitations of this model: no fluid properties and behaviour are taken into account. As consequence, no influence of frequency, pressure or viscosity can be studied.

\section{B. Algorithm}

\section{Notations:}

- The volume in a section $\mathrm{k}$ at the instant $t(i)$ is named $V_{i}(k)$

- The volume difference between two instants $t(i)$ and $t(i+1)$ for a section $k$ is named $D V_{i}(k)$.

- The volume leaving in inlet or outlet between two instants $t(i)$ and $t(i+1)$ are named respectively $V_{i n}(i)$ and $V_{\text {out }}(i)$

- At an instants $t(i)$, for an inter-section $s$, the height of the wall at the center in $\mathrm{y}$-direction is named $z_{i}(s)$

- Between two instants $t(i)$ and $t(i+1)$, from a section $k$ to a section $m$, for the $w$ step of the while loop, parts of volumes which go in direction of the inlet or outlet are named respectively $V_{i, k}^{i n}(w, m)$ and $V_{i, k}^{\text {out }}(w, m)$ (Fig.5)

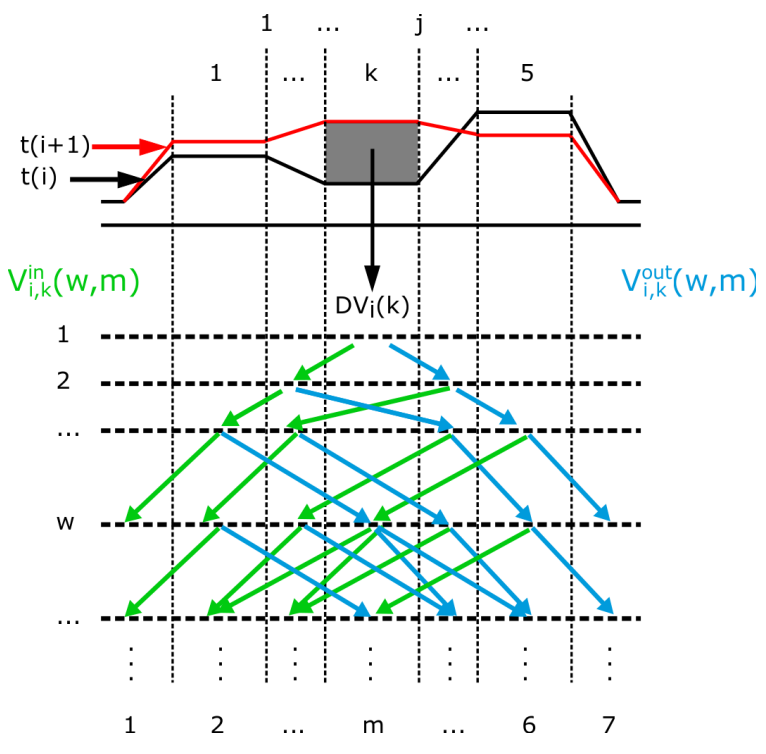

Fig. 5. Distribution of the volume difference towards inlet and outlet during the while loop

In detail, the $D V_{i}(k)$ of a section is evaluated to go in backward and forward sections in function of the height of inter-sections. It corresponds to the initialization of the matrix $V_{i, k}^{\text {in }}(w, m)$ and $V_{i, k}^{\text {out }}(w, m)$ (eq.2 and eq.3).

$$
\begin{aligned}
& \left\{\begin{array}{llr}
D V_{i}(k) & = & V_{i}(k)-V_{i+1}(k) \\
V_{i, k}^{\text {in }}(1, k+1) & = & D V_{i}(k) \\
V_{i, k}^{\text {out }}(1, k+1) & = & D V_{i}(k)
\end{array}\right. \\
& \left\{\begin{array}{l}
V_{i, k}^{\text {in }}(2, k) \\
V_{i, k}^{\text {out }}(2, k+2)=D V_{i}(k) \frac{z_{i+1}(k)}{z_{i+1}(k)+z_{i+1}(k+1)} \\
D V_{i}(k) \frac{z_{i+1}(k+1)}{z_{i+1}(k)+z_{i+1}(k+1)}
\end{array}\right.
\end{aligned}
$$

Then, for each inter-section $j$, a conflict occurs if the sum $V_{i, k}^{\text {out }}(w, m+1)+V_{i, k+1}^{\text {in }}(w, m)$ is not null. This sum is therefore redirected in the following step $w+1$ towards intersection $j-1$ and $j+1$ in function of their heights. With the notations described above, this principle is interpreted in recursive sequences in (eq.4) and illustrated in Fig. 5.

$$
\left\{\begin{array}{l}
V_{i, k}^{\text {in }}(w+1, j)= \\
\left(V_{i, k}^{\text {in }}(w, j+1)+V_{i, k}^{\text {out }}(w, j+2)\right) \frac{z_{i+1}(j)}{z_{i+1}(j)+z_{i+1}(j+2)} \\
V_{i, k}^{\text {out }}(w+1, j+3)= \\
\left(V_{i, k}^{\text {in }}(w, j+1)+V_{i, k}^{\text {out }}(w, j+2)\right) \frac{z_{i+1}(j+2)}{z_{i+1}(j)+z_{i+1}(j+2)}
\end{array}\right.
$$

From recursive sequences, the final volume inlet is the sum of first terms of $V_{i, k}^{i n}(w, m)$ and the final volume outlet is the sum of the last terms of $V_{i, k}^{\text {out }}(w, m)$ (eq.5).

$$
\left\{\begin{array}{lll}
V_{\text {in }}(i) & = & \sum_{w} \sum_{k} V_{i, k}^{\text {in }}(w, 1) \\
V_{\text {out }}(i) & = & \sum_{w} \sum_{k} V_{i, k}^{\text {out }}(w, \text { end })
\end{array}\right.
$$

The sequence (eq.4) is repeated until all volume differences between $t(i)$ and $t(i+1)$ are gone towards inlet or outlet (eq.6). 
These sums of (eq.5) must converge to the sum of $D V_{i}(k)$. With this simulated setup, less than 100 iterations per time step are needed to converge with an error inferior of $1 \%$.

$$
\left|V_{\text {in }}(i)+V_{\text {out }}(i)-\sum_{k} D V_{i}(k)\right|>e r r
$$

The algorithm is summarized in the pseudo-code below.

\section{Pseudo-code}

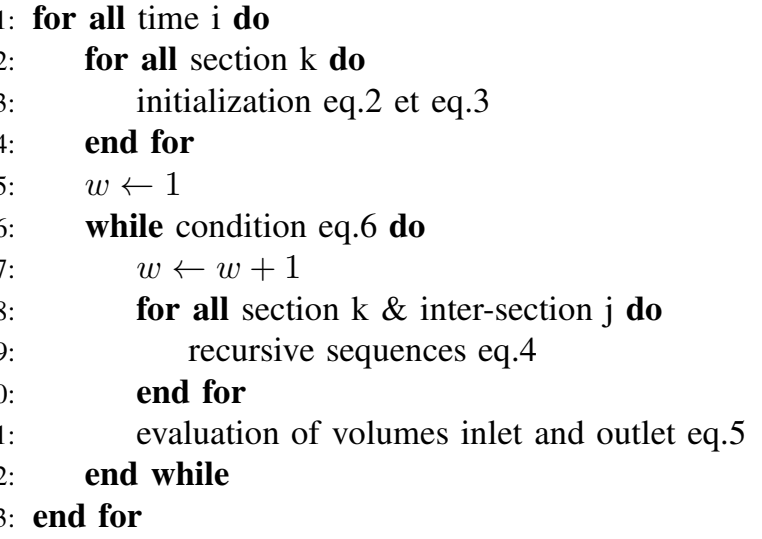

\section{CFD NUMERICAL SIMULATION}

Numerical resolution uses a segregated approach with implicit second order temporal discretization. The time step is chosen small enough to allow an accurate description of the wall movement: typically 100 time steps per period. A commercial finite volume code ( $\operatorname{starccm}+$ ) is used in this study.

We used a structured anisotropic mesh that is dynamically deformed in order to obtain the desired shape and movement of the top wall for the channel itself (around 150000 cells and about 20 cells along vertical direction). For inlet and outlet regions a polyhedral mesh was preferred (around 50000 cells each).

The following procedure is chosen to manage the mesh deformations: we first mesh a parallelepiped channel whose height is equal to the smallest height in the deformed configuration ( $5 \%$ of the channel height). Then this mesh is dilated to accommodate the displacement of the surface corresponding to the chosen wave. Using this procedure allows to only stretch the initial mesh and obtain a fair control of cell size at all times.

For the tested configuration we consider a transient 3D flow with a simple K-epsilon turbulence model. No-slip conditions are applied on all material surface, inlet and outlet pressure are fixed at atmospheric pressure. The considered fluid is water with constant properties (taken at $20^{\circ} \mathrm{C}$ ).

The upper channel wall displacement is prescribed using the same square functions than for the analytic case. Only half of the geometry is modelled, the system is supposed symmetric relative to the vertical plane parallel to the main flow axis in the channel. Actuators geometry is identical to the one used in the previous section.

A small (Fig. 6) length of tube is added to the system in order to place inlet and outlet boundaries conditions sufficiently

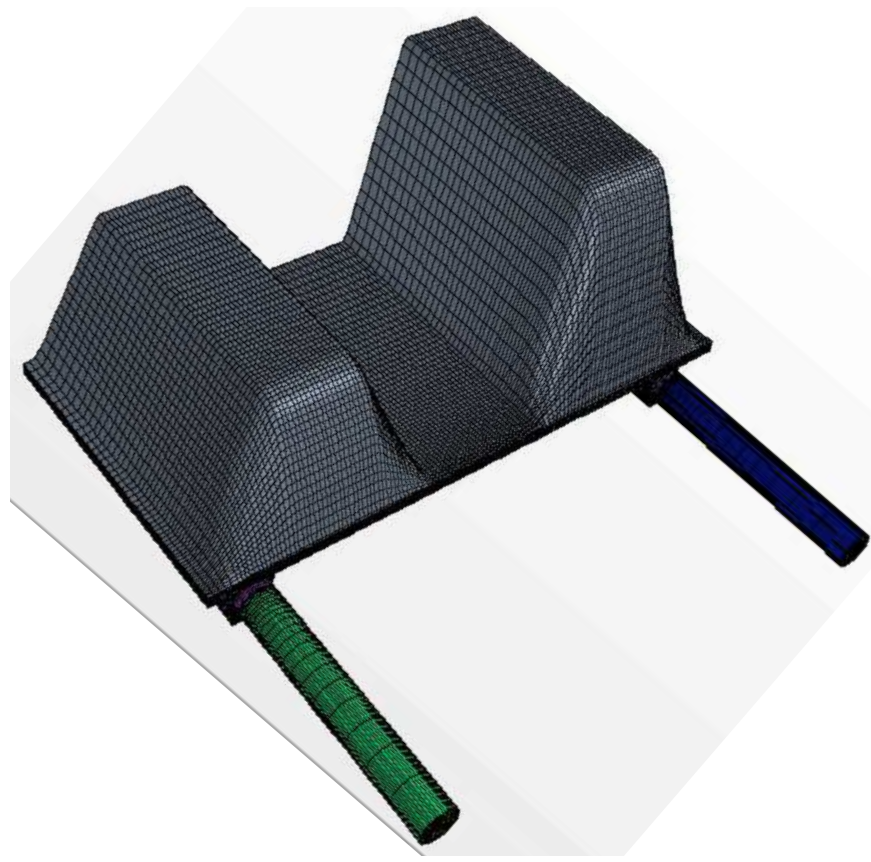

Fig. 6. Meshing of the fluid in 3D CFD simulations, with a scale multiplied by 100 in $\mathrm{z}$-direction

far from the region of interest and not induces bias on used results.

\section{RESULTS AND COMPARISON}

\section{A. General parameters}

Since computational model is independent of the frequency, results obtained over one period of time are linear with the frequency.

The width of footprints have been studied with the computational model. But no significant impacts are observed on the flow rate in the framework of this study.

To summarize, results below are obtained with the following simulated setup:

- the geometry represented in Fig. 3

- a frequency of $15 \mathrm{~Hz}$

- a square-like signal form identical for all three actuators

- a relative displacement of $95 \%$ of the channel height

\section{B. Study of instant volume inlet and outlet}

Results in Fig. 7 are obtained with phase shifts $\left(\Phi_{12} ; \Phi_{13}\right)=$ $\left(60^{\circ} ; 140^{\circ}\right) . \Phi_{12}$ and $\Phi_{13}$ being respectively the phase shift between actuators $1 \& 2$ and $1 \& 3$, counting in the x-direction. This case corresponds to the maximum flow rate with our simulated setup.

In Fig. 7 are presented the volumes $V_{\text {in }}(i)$ and $V_{\text {out }}(i)$ over a period of time. The sum of these volumes over the time represents the final volume which goes towards inlet or outlet. Because the deformation is periodical, these two sums are 


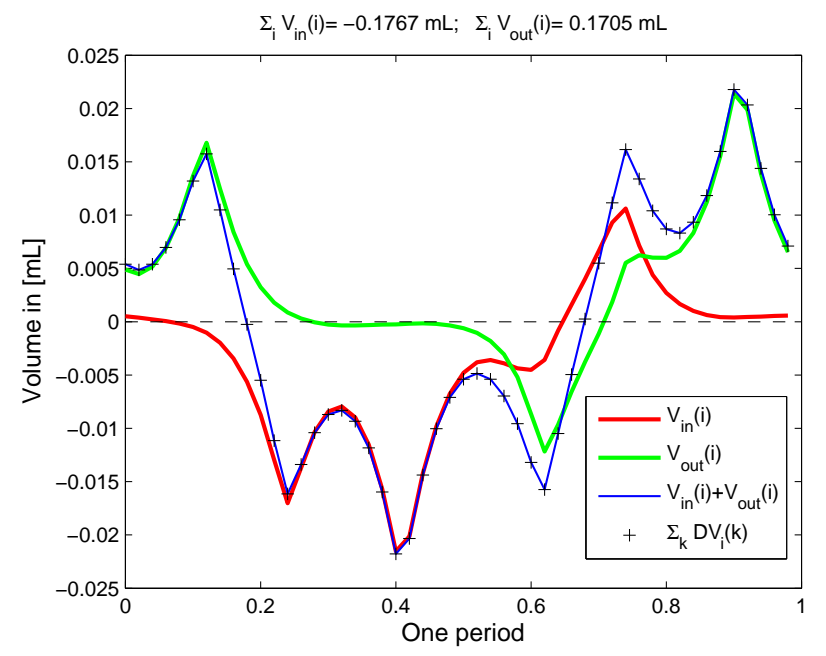

(a) computational method

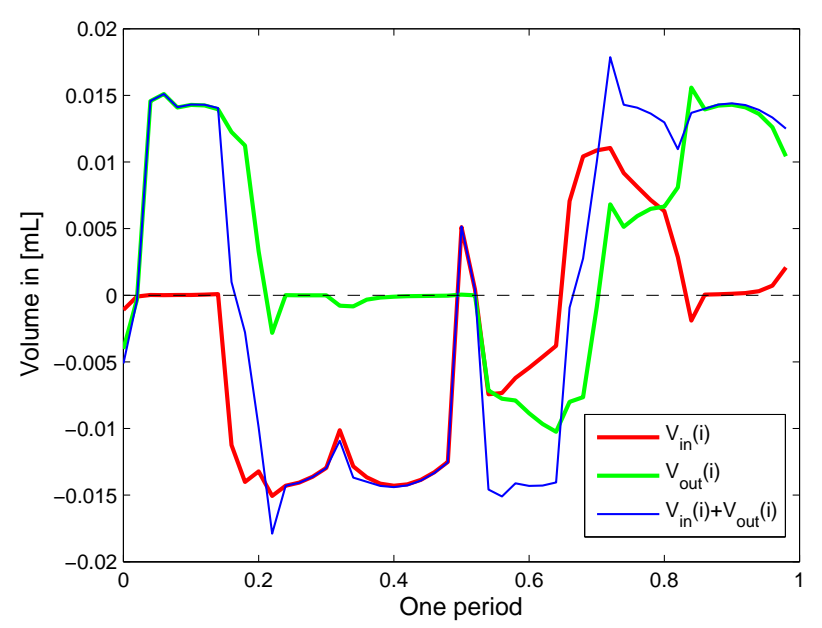

(b) CFD simulation

Fig. 7. Evaluation of instant volumes, in $m L$ for $60^{\circ}-140^{\circ}$ and 50 time steps over a period of time

opposed. It means that the volume which exits at the outlet comes from the inlet. $V_{\text {in }}(i)$ and $V_{\text {out }}(i)$ are not only negative or positive, which means that back flows occur, especially when the first actuator starts to close the channel ( 0.5 to 0.7 of the period of time).

It is also presented $\sum_{k} D V_{i}(k)$ and the sum of $V_{i n}(i)$ and $V_{\text {out }}(i)$ to verify the $1 \%$ of error.

The same behaviour is observed for both methods. Results from the computation method are naturally smoother than those with CFD simulation. The cause of peaks in Fig. 7b is the too few numbers of time steps.

\section{Study of phase shifts}

The Fig. 8 shows maps of the resulting flow rate $\sum_{i} V_{\text {out }}(i)$ calculated by varying the phase shifts between actuators $\left(\Phi_{12}\right.$ and $\left.\Phi_{13}\right)$. The same behaviour is observed with the two methods. The maximum and minimum flow rate are found with same configurations. The maximum error between these

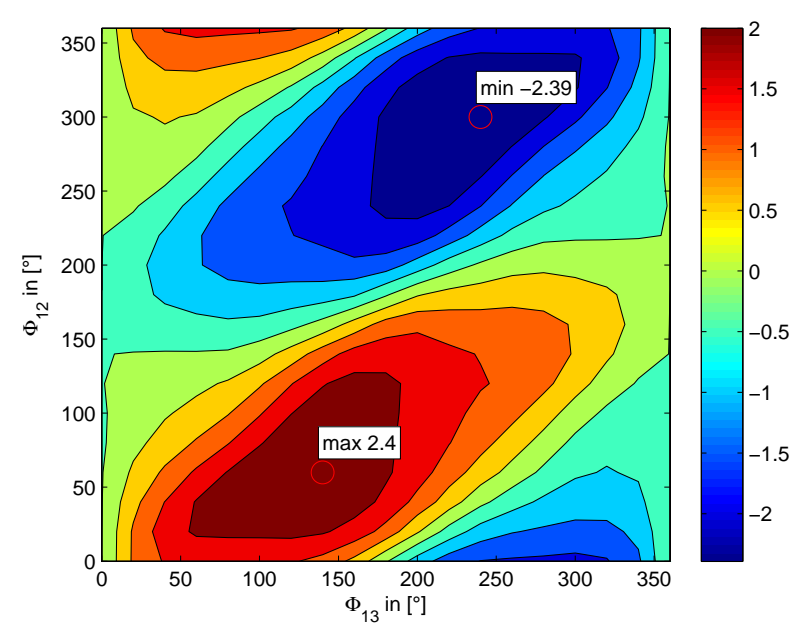

(a) computational method

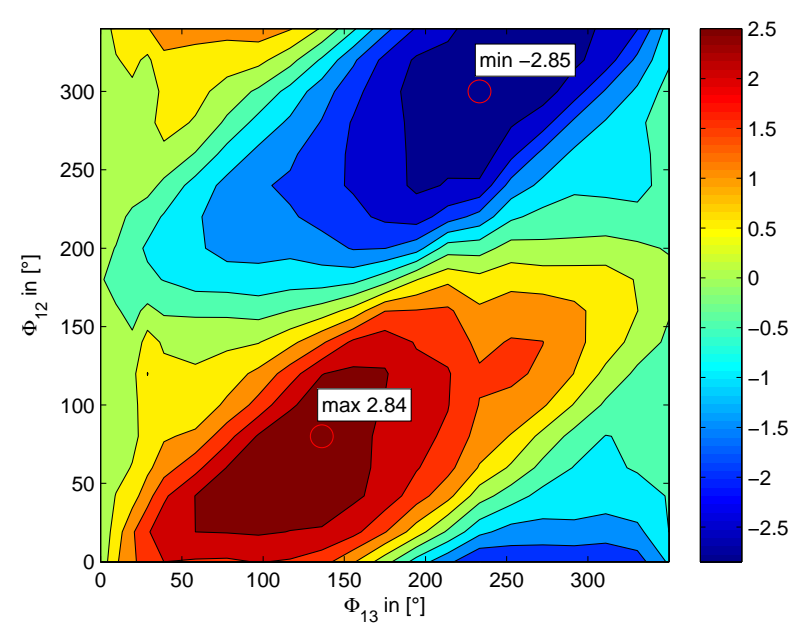

(b) CFD simulation

Fig. 8. Maps of flow rates, in $\mathrm{mL} / \mathrm{s}$ for all possible phase shifts, $15 \mathrm{~Hz}$, square signal form and $95 \%$ of relative displacement

maps is around $15 \%$. It is found for the maximum flow rate by avoiding the deviant points due to numerical approximation.

Because the geometry is symmetric, both maps have a central symmetry by taking the point $\left(180^{\circ} ; 180^{\circ} ; 0 \mathrm{~mL} / \mathrm{s}\right)$.

\section{Discussion}

These maps of flow rate (Fig. 8) validate the computational approach. Even if the instant volumes can be quite different (Fig. 7), the same behaviour is observed and the resulting flow rate are closed. The important point is that this error does not affect the global behaviour and the best configuration is found.

Additionally the use of this analytical approach is reinforced by its relative fast execution. Around $3 h$ are necessary to evaluate all results (324 cases) show in Fig. 8a with an average personal computer and the MatLab software. And for 3D CFD simulations (378 cases) showed in Fig. 8b, around $30 h$ are needed with the computational power of around 25 processors in parallel. 


\section{CONCLUSION}

This paper presents a specific pumping principle with the aim of using it in embedded system to cool a CPU. For this purpose a pseudo-travelling wave is produced by a set of actuators. In these conditions, the most constraining parameter is the flow rate. To evaluate this flow rate an computational model is developed. It allows to study the deformation parameters like signal form, amplitude displacement, phase shifts and also the geometry parameters(channel size, position of actuators...). This article is focused on the particular case of three actuators. The phase shift influence is explored as a flow rate control parameter. To validate the results from the computational method, a 3D CFD numerical simulation have been performed. The good accuracy of the model, its ease of use and its high speed computation make it a good solution to be implemented into an optimization algorithm preliminary analysis.

\section{ACKNOWLEDGEMENT}

This work has been realized in the framework of the CANOPEE project and supported by the "Fond Unique Interministériel (FUI) - 18th call for projects".

\section{REFERENCES}

[1] A. Danowitz, K. Kelley, J. Mao, J. Stevenson, and M. Horowitz, "Cpu db: recording microprocessor history," Communications of the ACM, vol. 55, no. 4, pp. 55-63, 2012.

[2] K. DeVogeleer, G. Memmi, P. Jouvelot, and F. Coelho, "Modeling the temperature bias of power consumption for nanometer-scale cpus in application processors," in 2014 International Conference on Embedded Computer Systems: Architectures, Modeling, and Simulation (SAMOS XIV), July 2014, pp. 172-180.

[3] J. M. Fontaine, F. Pigache, M. Miscevic, F. Topin, and J.-F. Rouchon, "Solutions d'actionnement pour méthodes actives de refroidissement des systèmes embarqués," in Société Française de Thermique, ser. 1, no. 103, 2016.

[4] J. Hoepffner and K. Fukagata, "Pumping or drag reduction?" Journal of Fluid Mechanics, vol. 635, pp. 171-187, 2009.

[5] L. Léal, F. Topin, P. Lavieille, L. Tadrist, and M. Miscevic, "Simultaneous integration, control and enhancement of both fluid flow and heat transfer in small scale heat exchangers: A numerical study," International Communications in Heat and Mass Transfer, vol. 49, pp. $36-40,2013$. [Online]. Available: //www.sciencedirect.com/science/article/pii/S0735193313002042

[6] K. Nakahara, M. Yamamoto, Y. Okayama, K. Yoshimura, and K. Fukagata, "A peristaltic micropump using traveling waves on a polymer membrane," Journal of Micromechanics and Microengineering, vol. 23, p. 7pp, July 2013, department of Mechanical Engineering, Keio University.

[7] X. C. Tong, Advanced Materials for Thermal Management of Electronic Packaging. Springer New York, 2011, vol. 30.

[8] F. Topin, L. Tadrist, M. Miscevic, P. Lavieille, L. Leal, B. Nogarede, F. Pigache, and M. Amokrane, "Conduit constitutif d'un echangeur de chaleur et echangeur de chaleur comprenant un tel conduit," Patent FR $2987107,0217,2012$. 